\title{
Opferstatus, Traumafolgen und Grundsätze der Traumatherapie aus psychologischer Sicht
}

Krammer, S ; Maercker, Andreas

Posted at the Zurich Open Repository and Archive, University of Zurich ZORA URL: https://doi.org/10.5167/uzh-66994

Book Section

Originally published at:

Krammer, S; Maercker, Andreas (2012). Opferstatus, Traumafolgen und Grundsätze der Traumatherapie aus psychologischer Sicht. In: Barton, S; Kölbel, R. Ambivalenzen der Opferzuwendung des Strafrechts : Zwischenbilanz nach einem Vierteljahrhundert opferorientierter Strafrechtspolitik in Deutschland. BadenBaden: Nomos, 251-263. 
Stephan Barton/Ralf Kölbel (Hrsg.)

Ambivalenzen der Opferzuwendung des Strafrechts

Zwischenbilanz nach einem Vierteljahrhundert opferorientierter Strafrechtspolitik in Deutschland 
Inhaltsverzeichnis

Vorwort

Einführung in den Band

Stephan Barton und Ralf Kölbel

\section{Bestandsaufnahme}

Internationale Entwicklungen bei der Stellung des Verletzten im Strafverfahren

Thomas Weigend

Opferschutz in der deutschen straf- und strafprozessrechtlichen Gesetzgebung und dessen Umsetzung in die Judikatur Wolfram Schädler

Opferrechte im Lichte europäischer Vorgaben Stefanie Bock

Zum Stand der internationalen viktimologischen Forschung

Thomas Görgen

Strafrechtspflege und Kriminalpolitik in der viktimären Gesellschaft. Effekte, Ambivalenzen und Paradoxien

Stephan Barton

\section{Primäre Viktimisierung}

Polizeiliches Verhalten bei Opfern von Sexualstraftaten am Beispiel der Opfer von Vergewaltigungen und sexuellen Nötigungen Wiebke Steffen 
Soziale Reaktionen auf primäre Viktimisierung: Zum Einfluss stereotyper Urteilsmuster

Zur opferorientierten Reform des Sexualstrafrechts.

Eine juristische Analyse

Thomas Fischer

\section{Sekundäre Viktimisierung}

Geschädigte im Strafverfahren: Positive Effekte oder sekundäre Viktimisierung?

Kriminalpolitische Instrumentalisierung der „Gefahr sekundärer Viktimisierung"?

Ralf Kölbel

Nebenklage - eine Erweiterung, keine Demontage des liberalen Strafverfahrens

Oliver Tolmein

\section{Tertiäre Viktimisierung}

Opferstatus, Traumafolgen und Grundsätze der Traumatherapie aus psychologischer Sicht Sandy Krammer und Andreas Maercker

Bewältigung krimineller Opfererfahrungen: Entwicklungsfolgen und Entwicklungsregulation Werner Greve, Sabine Hellmers und Cathleen Kappes 
Strukturelle und praktische Defizite der institutionalisierten Opferhilfe in Deutschland

Petra Ladenburger

Verzeichnis der Mitwirkenden 